Proceedings

\title{
Environmental monitoring of the historic city
}

Gaia Turchetti ${ }^{*}$

1 Università di Roma, La Sapienza 1;
* Correspondence: gturchetti@yahoo.it

Abstract: In recent decades, urban research and experimentation have analyzed the climate problem at various scales, in line with 'climate proof' policies aimed to verify the strategies proposed throughout the entire life cycle of the project and evaluate their 'efficient use', where 'use' stands for the identification of its potentialities and their translation in a planning act, for an 'integrated conservation' in relationship between urban morphology and urban climate. In this context, the research focuses on the definition and analysis of 'basic factors', whose monitoring is crucial for acting in accordance with the real needs of the site.

Keywords: historic city; monitoring; climate change; urban regeneration

\section{Introduction}

A sustainable development "is not a unvarying state of harmony, but rather a process of change" [1] (point 30) an extremely complex operation in which the real and operational 'sense' of the term "sustainable" - alongside by that of "development" - it is must no longer be sought only from an economic point of view, but increasingly embracing environmental issues as part of a collective need of change - thanks to a growing awareness of the processes and actors that determine it -, in a process which the word 'global' returns to be joined by a stronger sense of 'local'. All this must find space in the urban policies and strategies - and not only -, in its physical spaces which, now more than before, are learning to coexist with digital ones. Actual pandemic scenario, indeed, is determining new needs, new languages, and new models for the fruition and management of city both in the physical and digital fields -. The city as "third space", paraphrasing the words of Ray Oldenburg, that represents "the core settings of informal public life. [...] that host the regular, voluntary, informal, and happily anticipated gatherings of individuals beyond the realms of home and work." [2] (p. 16). So, the city is the territory for the (re)definition of cultural networks, a place for exchange and for training, research and good practices, where culture it fully fulfills its role as fourth pillar of sustainable development. [3] So, If we analyze the city as a 'relations system', a reality, paraphrasing Edgar Morin [4], not only physical but also geo-psycho-bio-human in which humans must relate the manifestation of their own necessities and freedoms to the responsibilities related to them, one wonders what are the system inputs and outputs [5] that determine the processes and changes, conditions of comfort and discomfort - starting from a necessarily interscalar evaluation - of the city as a complex 'urban room'. The challenge is therefore multilevel and multidisciplinary. At the level of policies and strategies, it is necessary to operate on a double level, a hierarchical one, from the macro-scale to the local and micro-scale, and a 'horizontal' one, of methodological and operational sharing between local realities, for a greater sharing and participation in the processes of change of urban space, especially addressed to climatic problems that see the city at the center of this challenge. [6].

Copyright: (C) 2022 by the authors. Submitted for possible open access publication under the terms and conditions of the Creative Commons Attribution (CC BY) license (https://creativecommons.org/license s/by/4.0/).

\section{Why the monitoring of environmental parameters. Why the historic city}

It is precisely by working on the management of these multiple cognitive-operational levels that a careful action of "mending" of the urban space must start (Piano, 2014), for its 'efficient use', where the word 'use' means the identification of its potential and 
their translation into a design act, for an 'integrated conservation' between morphology and urban climate. For each transformation process it is necessary to formulate project responses calibrated to specific socio-cultural and climatic needs [8] especially at local and micro level, and to the peculiarities of individual building fabrics, mainly the historical and consolidated ones [9]. The operational sensibility must necessarily increase in directly proportional relationship to the needs of urban space protection. In the project definition process, it is necessary to consider not only the efficiency and efficacy but also the quality of urban system [10] in terms of 'cultural performance', considering the main exhaustible resource at stake: the 'cultural heritage'. Spaces, social relationships, material, and immaterial testimonies of Cultural Heritage [11] are the engine of the definition of built space [12-13]. In the dual operational perspective, mentioned above, nodal is the finding, on a large scale and in a short time, of specific microclimatic data, fundamental element to act in accordance with the real needs of the site. The word 'monitoring' emerges more and more frequently in scientific discussions at the international level [14-15-16], not only as regards the 'process', in terms of evaluating the efficiency and effectiveness of the interventions, but also - and that's what matters here - as regards the knowledge of that complex system of inputs and outputs that define urban metabolism. To understand climate variability and change, the ability to observe and understand each component of the energy balance of the urban fabric from the local to the global scale is crucial, based on a complete monitoring of the climate system and radiative fluxes thanks to data in situ and spatial [17], starting from the macroscale (such as the data collected by the Copernicus program), to the local scale up to the microscale. It is above all these last data, or rather those at the microscale - although not easy to find - that represent for the designers a necessary tool for knowing the place, which cannot be ignored as this could compromise the real effectiveness of the hypothesized intervention, in how the lack of knowledge of the real data can compromise a correct reading and understanding of the possible benefits of the intervention, as well as alter the calculation of the comfort indices. This risk is higher in complex spaces such as those of the historic city, for which the actual entity of the data is often over or underestimated, leading to errors in evaluation both in the construction of the calculation models and in subsequent analyzes, such as the research presented here aims to highlight.

\section{An experiment on the historic city of Rome}

With this in mind, research was conducted, which began in the doctoral field and which still continues today also following the recent European and national directives on environmental issues and with educational contributions aimed to share the knowledge acquired on the subject. The research focuses on the analysis of one of these 'basic data', natural ventilation, which influences the comfort conditions of urban open space, highlighting 'if' and 'how' the anemometric factor is considered in the redevelopment processes of consolidated urban space, and 'how' and 'when' being able to exploit the potential of outdoor ventilation cooling are the basis for a wind strategy. The objective is to define an operational methodology that integrates this wind strategy into the design processes in urban areas, inserting itself in the steps proposed by the Adaptation Support Tool [18], and experimenting and operatively validating specific intervention models (Graphic 1). The main research questions are:

1. How to evaluate the ventilating factor in historical Italian urban tissues, different than the common case studies.

2. What are the effective tools in relation to the investigation field.

3. How to define a shared methodology that integrates the ventilating factor in the early stages of analysis, to remedy the lack of operational tools.

In order to answer the first question, a critical re-reading of the main researches and experiments on the broad-spectrum topic was carried out [19-20-21-22-23- et al] to build an international research framework and identify weaknesses on which to intervene. At the same time a morphometric analysis of historical city was made taking as a case study 
the historical city of Rome, in its different building fabrics. The morphometric analysis has allowed to define specific models of analysis. The second in-depth analysis has concerned survey tools. Starting from a first review of the existing ones we have come to select the most suitable for the specificities of historical tissues: directs, parametric, microscopic (CFD). For the direct survey, expeditious campaigns of microclimatic measuring in situ were made in some selected areas of the city. In parallel, tridimensional models of selected urban fabrics were constructed, analyzed with the software Envi-met (v.4.2). The direct data were compared with the simulated data to validate the models and calibrate the computational tool, in relation to the reliability of data and specific calculation problems of anemometric data. As has been shown, relying entirely on computational methods for the evaluation of the anemometric factor leads to underestimating, or in some cases overestimating, the parameter, leading to an incorrect microclimatic evaluation of the analyzed environment, mainly in complex areas, such as historical ones, such as It also arises from interesting studies carried out at the international level [20-24-25] and as is also verified in the research here presented of the Italian case. Finally, to answer the third question, starting from the emerged problems, it has been defined 'ideal models' that reproduce the same morphometric relationships of tissues, simplifying some problematic morphological aspects. These models have been tested on real fabrics and in relation to different scenarios of urban transformation. The results obtained hitherto lead us to consider these models, and the methodology for their construction, as a useful and reliable tool for a multicriteria definition of urban transformations. [26].

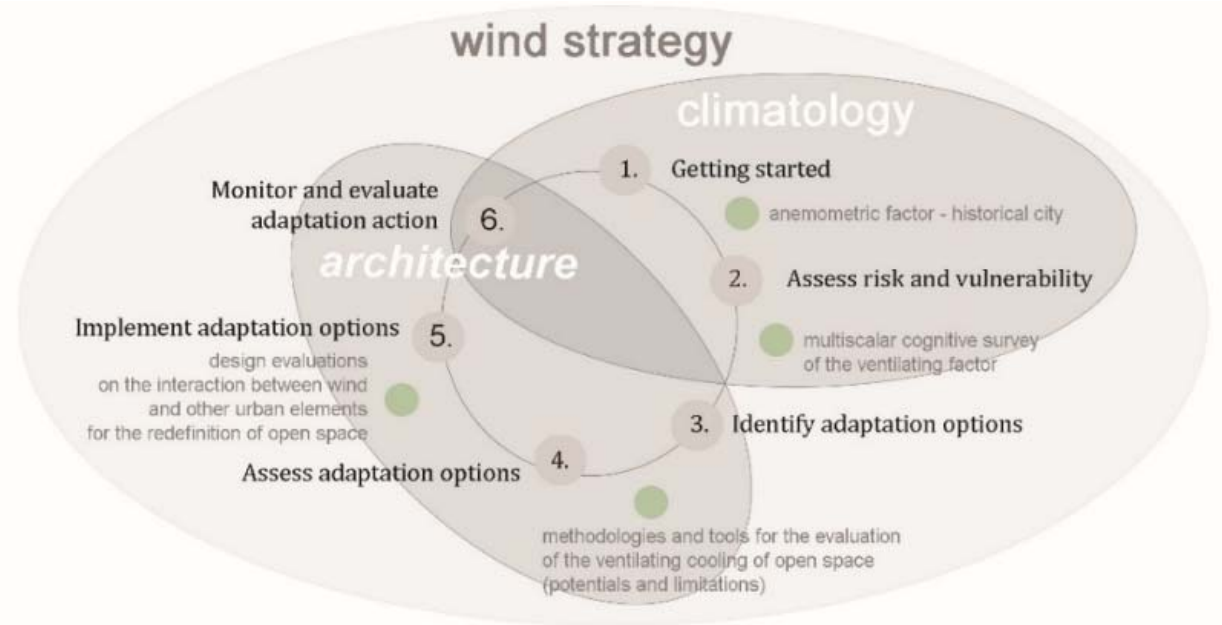

Figure 1. I Starting from the "interconnected fields of climatic balance" proposed by Olgyay [27] and crossing them with the main steps proposed in the Adaptation Support Tool-EEA [18], an interesting synoptic table is obtained that shows the multiscalarity and multidisciplinarity of the climate adaptation process, where the research work comes in (sub-points in green). ( ) G. Turchetti

\section{Discussion and conclusion.}

Starting from the definition of the key elements to the analysis of the inquiry tools - recalibrated for the specific historical area studied - we arrive to the design experimentation in specific selected areas, proposing and validating specific intervention models. Through a trial and error process, which accompanies the designer from the first analysis phases to the project evaluation, we wanted to define a shareable methodological tool and survey sheets that integrate the ventilation factor in the decision-making process for redefinition of urban space, useful to help partly fill the identified methodological-operational gap, promote collaboration between the different subjects involved in the processes of urban transformation at different levels and define a synthetic epistemology. Through a trial and error process, which accompanies the designer from the first analysis phases to the project evaluation, we wanted to define a shareable methodological tool and survey sheets that integrate the ventilation factor in the decision-making process for 
redefinition of urban space, useful to help partly fill the identified methodological-operational gap, promote collaboration between the different subjects involved in the processes of urban transformation at different levels and define a synthetic epistemology. Aware that the contributions of ventilation are not determinants of a situation of urban discomfort, what we want to contribute is one more piece to add to the already more consolidated knowledge regarding other design practices aimed to improve the urban microclimate, evaluating the different integrations between air flows and the urban structure as a whole. Therefore, it arises that the operational relapses of the investigation are directed mainly to the designer and the public administration, as subjects that operate at the urban level in the operations of 'repair' of the historical fabric of the city, not to standardize the behavior or the project actions - which would distort the concept of an architectural project and especially the integration of this project in extremely fragile fabrics, such as historical ones - but to systematize an analysis methodology that implements the knowledge bases for a correct projectual action.

\section{References}

1. WCED, Our Common Future. Univ. Press: Oxford, 1991

2. Oldenburg, R. The Great Good Place. Da Capo Press: Philadelphia, 2005.

3. UCLG, (2010), Culture is the Fourth Pillar of Sustainable Development. Available online: http://www.agenda21culture.net/documents/culture-the-fourth-pillar-of-sustainability (october 2020)

4. Morin, E. L anno I dell'era ecologica. Spadolini B. (Trad.). 2007. Armando Editore: Roma.

5. Wolman A. Metabolism of Cities. In Scientific American. 1965. 213, 3, 156-174

6. Tucci, F. Rapporto. Verso la neutralità climatica delle Green City. Approcci, indirizzi, strategie, azioni. 2021. Available online: https://www.greencitynetwork.it/il-26-ottobre-la-neutralita-climatica-delle-green-city/

7. Piano, R. Diversamente politico. Il nostro futuro è nella parte fragile delle città. Così è nato il G124, in Periferie. Diario di un rammendo delle nostre città. Report 2013-2014. G124. 2014

8. Castellari S. L'Europa verso l'adattamento ai cambiamenti climatici. 2012. Ecoscienza 2, 8-11

9. Filpa, A. La carta della vulnerabilità climatica di Roma 1.0. in ISPRA Ambiente X Rapporto. Le città e la sfida dei cambiamenti climatici. 2014. ISPRA: Roma.

10. Tucci, F. Passive Cooling in Mediterranean Area for a Bioclimatic and Zero Energy Architecture. In Sayigh, A. (eds), Mediterranean Green Buildings \& Renewable Energy. 2017. Springer International Publishing Switzerland: Cham.

11. CdE-Council of Europe. Convention on the Value of Cultural Heritage for Society (Faro Convention). 2015. CdE: Strasbourg.

12. Carmona M. Urban Design Reader. 2007. Elsevier: Oxford.

13. Carmona M. Public Places, Urban Spaces: The Dimensions of Urban Design. 2010. Elsevier: Oxford.

14. UNHABITAT. World Cities Report 2020: the Sustainable Development Goals Report. 2020. United Nations. Available online: https://unhabitat.org/sites/default/files/2020/09/the-sustainable-development-goals-report-2020-.pdf

15. WMO. 2020 State of Climate Services Report. 2020. Available online: https://library.wmo.int/doc num.php?explnum id=10385

16. Presidenza del Consiglio dei Ministri. Piano Nazionale di Ripresa e Resilienza (PNRR). 2021. Available online: https://www.governo.it/sites/governo.it/files/PNRR.pdf

17. IPCC. AR6 Scoping Meeting Addis Ababa, Ethiopia, 1 - 5 May 2017. IPCC Secretariat: Geneva, Available online: https://www.ipcc.ch/site/assets/uploads/2018/11/AR6-Chair-Vision-Paper.pdf

18. EEA. Urban adaptation to climate change in Europe. Report 2/2012. Off. Official Publ. of the European Union: Luxembourg.

19. Mills, Bechtel, Foley, Ching, See, Feddema. The WUDAPT Project: Status of Database and Portal Tools. Proceedings of 12th Symposium of the Urban Environment. 2017.

20. Salata, Golasi, de Lieto Vollaro et al. Urban microclimate and outdoor thermal comfort. A properprocedure to fit ENVI-met simulation outputs to experimental data. Sustainable Cities and Society. 2016, 26, 318-343.

21. Acero J.A., Herranz-Pascual K. A comparison of thermal comfort conditions in four urban spaces by means of measurements and modelling techniques. Building and Environment. 2015, 93, 245-

22. Erell, E., Pearlmutter, D., Williamson, T. Urban Microclimate: Designing the Spaces Between Buildings. 2011 Earthscan: London.

23. Santamouris. M. Heat Island Research in Europe: The State of the Art. Advances in Building Energy Research. 2007, 123-150.

24. Bröde, P. and Fiala, D. Deriving the operational procedure for the Universal Thermal Climate Index (UTCI), International Journal of Biometeorology, 2012, 56, 3, 481-94.

25. Park, S., Tuller, S.E. and Jo, M. Application of Universal Thermal Climate Index (UTCI) for microclimatic analysis in urban thermal envi-ronments. Landscape and Urban Planning. 2014, 125, 146-155.

26. Turchetti, G. Qualità ambientale della città storica: la sfida della wind strategy". TECHNE Journal of Technology for Architecture and Environment. 2020,19, 203-212

27. Olgyay V. Progettare con il clima: un approccio bioclimatico al regionalismo architettonico. 1981. Muzio Editore: Padova. 